НАЗЕМНЫЕ КОМПЛЕКСЫ, СТАРТОВОЕ ОБОРУДОВАНИЕ, ЭКСПЛУАТАЦИЯ ЛЕТАТЕЛЬНЫХ АППАРАТОВ

Посвящуается 60-летию начала полетов ракеты $P-7$, ставшей основой отечественной космонавтики, и 55-летию первого полета человека в космос.

DOI: $10.18698 / 0236-3941-2016-2-7-27$

УДК 629.7.085:621.59

ОСОБЕННОСТИ СОЗДАНИЯ И РАЗВИТИЯ КРИОГЕННЫХ СИСТЕМ РАКЕТНО-КОСМИЧЕСКИХ СТАРТОВЫХ КОМПЛЕКСОВ “СОЮЗ”

\author{
А.А. Александров ${ }^{1}$, И.В. Бармин ${ }^{1,2}$, И.Д. Кунис ${ }^{2}$, В.В. Чугунков ${ }^{1}$ \\ ${ }^{1}$ МГТУ им. Н.Э. Баумана, Москва, Российская Федерация \\ e-mail:sm8@sm8.bmstu.ru \\ ${ }^{2}$ ЦЭНКИ, Москва, Российская Федерация
}

Рассмотрены вопросы производства, транспортирования, хранения с наименьшими потерями криогенных продуктов - жидких кислорода и азота, заправки ими топливных баков ракет, охлаждения жидким азотом углеводородного горючего при создании и эксплуатации криогенных систем ракетно-космических стартовых комплексов для ракет серии “Союз”. Приведены сведения о предприятиях и специалистах, участвовавших в разработке материалов и криогенного оборудования, проведении исследований и создании криогенных систем. Отмечены особенности прочессов, происходящих на переходных режимах при транспортировании криогенных жидкостей по трубопроводам криогенных заправочных систем, а также особенности возникновения интенсивных гидроударов. Рассмотрены вопросы конструирования резервуаров и трубопроводов криогенных систем и повышения эффективности их изолящии. Приведены характеристики криогенных систем стартового комплекса ракеты “Союз-СТ”.

Ключевые слова: стартовый ракетный комплекс, криогенные заправочные системы, криогенные системы охлаждения горючего.

\title{
CHARACTERISTIC FEATURES OF CREATING \\ AND DEVELOPING CRYOGENIC SYSTEMS OF SPACE-ROCKET LAUNCH COMPLEX "SOYUZ"
}

\author{
A.A. Aleksandrov ${ }^{1}$ ， I.V. Barmin ${ }^{1,2}$ ， I.D. Kunis ${ }^{2}$, V.V. Chugunkov ${ }^{1}$ \\ ${ }^{1}$ Bauman Moscow State Technical University, Moscow, Russian Federation \\ e-mail:sm8@sm8.bmstu.ru \\ ${ }^{2}$ Centre of Ground Space Infrastructure Exploitation, Moscow, Russian Federation
}

Implementation of flight into outer space in addition to constructing spacecraft and rockets, requires the solution of many complex scientific and technical problems when getting ready to the launch. The complex of such issues includes production, transportation to the launch site, storage with minimal loss of cryogenic products -

ISSN 0236-3941. Вестник МГТУ им. Н.Э. Баумана. Сер. "Машиностроение” 2016. № 27 
liquid oxygen and liquid nitrogen, flling the rocket fuel tanks, cooling hydrocarbon fuel with liquid nitrogen and safeguarding of the rocket cryogenic components. The aim of this research is to analyze all the problems listed above. We examine companies and professionals involved in developing the materials and cryogenic equipment, conducting research and creating the cryogenic systems. Thus, we emphasize some characteristic features of the processes occurring under transient conditions during the transportation of cryogenic liquids by pipeline cryogenic gas systems. Moreover, we consider the causes of intense water hammer, leading to the cryogenic equipment destruction, carry out a full review of the tanks and pipelines design of cryogenic systems and propose methods of improving the efficiency of the system insulation. The study tested the technology of cooling hydrocarbon rocket fuel in cryogenic systems, launch complexes through the non-contact heat exchange with liquid nitrogen and schemes of their implementation. The findings of the research show the calculated dependences and the results of the simulation temperatures, as well as the data on the relative costs of liquid nitrogen when performing the operation of cooling hydrocarbon rocket fuel in the cryogenic equipment. As a result, we obtain the cryogenic system characteristics of the launch complex "Soyuz-ST".

Keywords: launch complex, cryogenic filling system, cryogenic fuel cooling system.

Осуществление полета в космическое пространство помимо создания космического аппарата и ракеты требует решения многих сложных научных и технических проблем по подготовке к старту. К комплексу подобных проблем относятся производство, транспортирование на стартовый комплекс, хранение с минимальными потерями криогенных компонентов ракетного топлива и сжиженных технологических газов, а также заправка топливных баков ракет-носителей и разгонных блоков.

Криогенные компоненты ракетного топлива (КРТ) позволяют получать в камерах сгорания (КС) жидкостных ракетных двигателей (ЖРД) значительно более высокие удельные импульсы, чем при использовании только высококипящих КРТ [1]. Кроме того, в отличие от высококипящих КРТ, криогенные компоненты (за исключением фтора, который не получил применения из-за высокой токсичности) не токсичны и не загрязняют окружающую среду.

Однако высококипящие КРТ могут храниться при обычных температурах в резервуарах наземных систем и баках ракеты, низкокипящие же компоненты (жидкие кислород и фтор как окислители, жидкий водород и сжиженный природный газ как горючие), имеющие температуру существования ниже $120 \mathrm{~K}$, требуют особых условий хранения и эксплуатации. Следует иметь в виду, что процессы, происходящие в криогенных заправочных системах стартовых ракетных комплексов, существенно отличаются от процессов, происходящих при заправке ракет высококипящими КРТ.

Низкие температуры криогенных жидкостей обусловливают неизбежные теплопритоки из окружающей среды, которые в сочетании с малыми значениями теплоты фазовых переходов, а также малым диапазоном существования в жидком состоянии, приводят к непрерывному изменению их параметров, усиливают возможность фазовых переходов и потери продуктов.

8 ISSN 0236-3941. Вестник МГТУ им. Н.Э. Баумана. Сер. “Машиностроение”. 2016. № 2 
В жидкостных криогенных системах практически отсутствуют стационарные режимы работы, в которых параметры продукта остаются неизменными, а процессы на переходных режимах отличаются сложностью и многообразием форм. Возникающие при этом динамические нагрузки имеют высокую интенсивность. В случае недостаточного первоначального прогрева жидкости в потоке появляется паровая фаза компонента и ее параметры существенно изменяются, увеличивая нагрузки на оборудование. Методы эффективного использования, а также негативные и опасные факторы и явления, способные возникнуть при эксплуатации криогенного оборудования на стартовых комплексах, необходимо учитывать при создании и выборе режимов его эксплуатации. Далее кратко приведем опыт эффективных решений перечисленных проблем при создании и эксплуатации криогенных систем ракетно-космических комплексов для ракет серии “Союз” на основных этапах их создания и развития.

Особенности создания и развития криогенных заправочных систем на комплексах межконтинентальной ракеты Р-7 и ракетносителей, созданных на ее основе. Для первых отечественных ракетных комплексов баллистических ракет Р-1, Р-2, Р-5М, межконтинентальной ракеты Р-7 и ракет-носителей, созданных на ее основе и обеспечивших выведение в космическое пространство первых беспилотных и пилотируемых космических аппаратов, потребовалось создание криогенных кислородных и азотных систем.

Как окислитель жидкий кислород был применен в ЖРД еще в 1930-е годы. Во время Второй мировой войны его использовали в немецких боевых баллистических ракетах ФАУ-2. Сейчас жидкий кислород как окислитель используется в большинстве ракет космического назначения как у нас в стране, так и за рубежом.

До 1931 г. СССР не имел собственной машиностроительной базы для производства воздухоразделительных установок. Первая отечественная установка для получения кислорода была разработана и изготовлена в 1932 г. (С.Я. Герш, Н.А. Доллежаль, С.Н. Семихатов). С 1933 г. началось строительство кислородно-азотных добывающих заводов. Основополагающие работы по созданию воздухоразделительных установок были выполнены в институте физических проблем АН СССР под руководством академика П.Л. Капицы. В 1942 г. создан “Главкислород" во главе с П.Л.Капицей. В 1943-46 гг. организованы научно-исследовательский институт кислородного машиностроения (НИИКимаш) и специализированные заводы.

Развитие техники низких температур требовало совершенствования подготовки специалистов криогенной техники учебными заведениями страны, в том числе и МВТУ им. Н.Э. Баумана, где появились 
научные школы в области криогеники. В дальнейшем в стране были разработаны крупные воздухоразделительные установки, позволившие создать кислородно-азотные заводы различной производительности (до 6 т/ч) жидкого кислорода и азота. Это дало возможность бесперебойного снабжения стартовых комплексов жидкими кислородом и азотом. Сейчас функционируют порядка 40 таких заводов.

В СССР к работам по созданию боевой ракетной техники, криогенных систем для стартовых комплексов и освоению космического пространства был привлечен ведущий институт страны в области кислородной, а затем криогенной техники - ВНИИКимаш. В 1947-48 гг. этот институт наряду с конструкторскими бюро ОКБ-1 (разработчик ракет) и ГСКБ “Спецмаш” (в последствии Конструкторское бюро общего машиностроения (КБОМ) - головной разработчик стартовых комплексов) был привлечен к разработке и созданию оборудования для заправки ракет P-1, P-2, а затем P-5M и Р-7 и ее модификаций жидким кислородом и азотом.

Прежде всего, необходимо было создать емкостное оборудование для хранения низкотемпературных компонентов в кондиции и с малыми потерями, разработать способы подачи этих продуктов в баки ракеты в условиях теплопритоков извне, создать материалы, стойкие при низких температурах, соответствующую арматуру, теплообменную аппаратуру, приборы и многое другое.

До конца 1950-х годов кислород и азот перевозили и хранили в резервуарах с насыпной изоляцией из магнезии, мипоры или шлаковой ваты. Ввиду малой эффективности такой изоляции потери криогенных продуктов достигали 6.. 10 \% в сутки, поэтому были начаты работы по созданию более совершенной вакуумной и порошково-вакуумной изоляции.

В институте изучались процессы охлаждения жидкого кислорода, тепло- и массообменные процессы в наземном криогенном оборудовании, а также процессы, происходящие в баках ракеты при ее заправке, изучались температурные поля (температурная стратификация) в цилиндрических сосудах и т.п.

Основными металлами, используемыми в то время в низкотемпературной технике, были медно-цинковые сплавы. Из них были выполнены коммуникации и арматура для первых стартовых комплексов ракеты Р-7 на космодромах “Байконур” и “Плесецк”. Применение обычных углеродистых сталей здесь было недопустимо из-за резкого уменьшения ударной вязкости металлов при низких температурах (охрупчивания), а также снижения пластичности и усталостной прочности. Результатами совместных работ по низкотемпературной технике, выполняемых во ВНИИКимаше и ВНИИчермете в конце 1950-х

10 ISSN 0236-3941. Вестник МГТУ им. Н.Э. Баумана. Сер. “Машиностроение”. 2016. № 2 
годов, явились создание ферритной стали марки 06Н3 с низким содержанием никеля и технология ее автоматической сварки под флюсом (совместно с институтом электросварки им. Е.О. Патона). Также были проведены исследования и даны рекомендации по применению оловянно-свинцовых припоев, а затем создана совместно с металлургами и более совершенная никелевая коррозионно-стойкая сталь.

В 1949-1953 гг. в отделе главного конструктора ВНИИКимаша Б.С. Жданова были созданы заправщики и подпитчики жидкого кислорода для комплексов ракет Р-2 и Р-5.

В 1954 г. во ВНИИКимаше было создано ОКБ, где сосредоточилась вся дальнейшая работа по космическим системам (руководители Б.С. Жданов и Д.И. Талалов).

В 1953-1956 гг. по техническому заданию ОКБ-1, согласованному с ГСКБ “Спецмаш”, в ОКБ ВНИИКимаша были разработаны, а затем построены первая жидкостная стационарная система заправки первой межконтинентальной ракеты Р-7 жидкими кислородом и азотом, обеспечивающая заправку и подпитку первой и второй ступеней ракеты при подготовке к старту, а также агрегат, обеспечивающий стартовый комплекс и ракету азотом высокого (24 МПа) давления и состоящий из четырех газификационных установок СГУ-7 Одесского объединения “Кислородмаш”. Хранение 200 т жидкого кислорода и нескольких тонн азота было осуществлено в цилиндрических резервуарах, изолированных стекломатами с потерями менее $5 \%$ в сутки. Жидкий кислород в топливные баки ракеты подавался четырьмя центробежными насосами по латунным трубопроводам, теплоизолированным мипорой и киперной лентой. Хранилище пополнялось из построенного на старте кислородного завода (позднее законсервированного) и железнодорожных цистерн, изготовленных на Уральском вагоностроительном заводе (г. Нижний Тагил). Подача в ракету жидкого азота осуществлялась вытеснением газообразным азотом, подаваемым из газовых хранилищ стартового комплекса.

Смонтированные на первом стартовом комплексе космодрома “Байконур" такие системы в числе других обеспечили решение задач по выводу на орбиту вокруг Земли первого искусственного спутника, полет первого человека в космос, полеты космических аппаратов различного назначения вокруг Земли и в дальний космос.

Через несколько лет были созданы четыре стартовых комплекса для пуска ракет типа Р-7 на космодроме “Плесецк” и второй комплекс на космодроме “Байконур”. Криогенное оборудование для них было создано по чертежам ВНИИКимаш, аналогично первому.

В 1953-1963 гг. возникла проблема перевозки криогенных топлив с заводов на полигоны. Для создания железнодорожных средств перевозки криогенных продуктов были привлечены специалисты Уральского вагоностроительного завода, где имелся опыт создания грузовых 
железнодорожных вагонов. Необходимо отметить, что руководство этого завода новый заказ приняло в штыки и делало все возможное для отказа от этой работы. И лишь усилиями академиков С.П. Королева и В.П. Бармина удалось убедить руководство создать на этом заводе новое КБ (ОКБ-250) во главе с М.Н. Веремьевым и осуществить разработку и производство железнодорожных агрегатов для перевозки жидких кислорода и азота с совершенной порошково-вакуумной изоляцией, обеспечивших доставку на стартовые комплексы криогенных компонентов топлива.

Начиная с 1950-х годов это подразделение Уральского вагоностроительного завода превратилось в современное предприятие, создававшее не только железнодорожные средства перевозки криогенных жидкостей (включая жидкий водород), но и автомобильные заправщики-перевозчики низкотемпературных жидкостей, а также стационарные заправочные криогенные системы.

На предприятии проводились не только новые конструкторские разработки, но и научные работы (в частности, по водороду высокого давления). По существу, на этом заводе была создана новая отрасль отрасль криогенного машиностроения со своим сборочным цехом и лабораторией.

В то же время во ВНИИКимаше было разработано и освоено производство автомобильных цистерн различного объема. В этих цистернах можно было перевозить жидкие кислород и азот и на железнодорожном транспорте. Впервые в криогенной технике был внедрен легкий алюминиевый сплав АМГ-6, освоена его сварка, созданы биметаллические переходники и совершенная изоляция.

В целях интенсификации работ по криогенной тематике, и в первую очередь, для ракетно-космической техники, в 1967 г. на базе балашихинского филиала ВНИИКимаша и машиностроительного завода им. 40-летия Октября был создан головной институт в области криогенной техники - научно-исследовательский институт криогенного машиностроения "ВНИИкриогенмаш” (в последствии НПО и ОАО “Криогенмаш”), состоящий из научно-исследовательского института, машиностроительного завода и опытного производства, на который возлагалось выполнение научно-исследовательских, проектных, опытно-конструкторских работ, изготовление, испытание и отладка разнообразного криогенного оборудования, в том числе для наземных систем ракетно-космических комплексов.

Директором и генеральным конструктором объединения был назначен крупный ученый, член-корреспондент АН СССР В.П. Беляков. Следует обратить внимание, что В.П. Беляков, создавая крупный научный центр криогенной техники, подчинил опытное производство

12 ISSN 0236-3941. Вестник МГТУ им. Н.Э. Баумана. Сер. “Машиностроение”. 2016. № 2 
и машиностроительный завод задачам научно-исследовательского института (а не наоборот, как часто имеет место сейчас). Это способствовало созданию криогенного оборудования высокого уровня, не уступающего иностранному, а иногда превосходящего его.

В целях создания совершенного криогенного заправочного оборудования многие технические вопросы пришлось решать впервые, для этого требовались проведение крупных научно-исследовательских и конструкторских работ и стендовая отработка.

Поэтому в лабораториях и конструкторских отделах Криогенмаша под общим руководством В.П. Белякова и его первого заместителя Н.В. Филина были проведены такие работы. Особое внимание было уделено исследованию процессов, происходящих на переходных режимах при транспортировании криогенных жидкостей.

На переходных режимах работы криогенных систем наряду с процессами, характерными для неустановившегося движения однофазной высококипящей жидкости, возникают процессы, типичные только для криогенных жидкостей. Их многообразие и интенсивные динамические нагрузки при этом приводили к отказам и даже разрушениям оборудования криогенных систем, а иногда и топливных систем ракеты.

На переходных режимах, когда в системе резко повышается давление, происходит интенсивное заполнение паровых полостей. Конденсация паровой фазы на границе газ-жидкость, которая становится существенно недогретой по отношению к повышенному давлению, способствует возникновению гидравлического удара с амплитудой, на порядок и более превышающей первоначальное возмущение. Близкое к этому (повышенный гидроудар) происходит и при открытии клапанов криогенных систем. Это связано с прекращением и возобновлением через некоторое время подачи жидкости в систему заправки [1].

Особенно интенсивные гидроудары возникают, когда клапан, открывающийся против потока, под действием жидкости вновь перекрывает проходное сечение. В ОАО “Криогенмаш" были проведены исследования причин возникновения повышенных гидроударов в различных элементах криогенных систем, созданы математические модели расчетов и разработаны меры борьбы с ними, обеспечившие безаварийность работы всех криогенных заправочных систем ракетнокосмических комплексов.

Экспериментально были исследованы процессы, возникающие при подаче криогенной жидкости в “теплую” магистраль. Установлено, что по мере продвижения жидкости по магистрали и ее прогреве поток распадается и, если пропускная способность по пару становится недостаточной, наступает режим запирания с повышением давления и 
обратным выбросом жидкости в резервуар. Результаты экспериментальных исследований показали, что наибольшие динамические нагрузки возникают на этапе первого броска жидкости, на который и следует ориентироваться при расчетах.

Помимо этого проводились исследования по повышению эффективности изоляции резервуаров и трубопроводов, в том числе экранновакуумной:

- исследованы и даны рекомендации по обеспечению надежного дренажа паров криогенных продуктов, определены безопасные расстояния выбросов;

- исследованы вопросы рассеяния паров криогенных продуктов при их проливах с открытой поверхности, разработаны меры безопасности, определен тротиловый эквивалент возможного взрыва;

- разработаны рекомендации безопасного обращения с криогенными продуктами;

- установлены наиболее эффективные адсорбенты, поглощающие газы, выделяемые из вакуумных полостей резервуаров и трубопроводов, или попадающие туда через неплотности;

- созданы методика и программы расчета сложных криогенных систем применительно к системам заправки ракет-носителей, разгонных блоков и космических аппаратов, основанные на математическом описании сложных волновых процессов и физических особенностей, возникающих в исследуемой системе;

- созданы унифицированные ряды оборудования, из которых можно комплектовать криогенные системы в зависимости от назначения и исходных данных для различных отраслей промышленности;

- разработаны ряды стационарных и передвижных резервуаров для хранения и выдачи потребителям криогенных продуктов, как горизонтальных, так и вертикальных, заводского изготовления, объемом от 5 до 250 м $^{3}$ с экранно-вакуумной (ОАО “Криогенмаш”) и порошкововакуумной изоляцией (ОАО “Уралкриомаш”);

- в ОАО "Криогенмаш" созданы типовые конструкции секций двухстенных криогенных трубопроводов различных диаметров, вплоть до 400 мм, с экранно-вакуумной изоляцией. Секции таких трубопроводов свариваются друг с другом на объекте, на месте монтажа, с получением более длинных (до 100 м) участков с автономными изоляционными полостями. Вакуумирование таких полостей проводится на объекте, что требует большого числа установок вакуумирования и значительного времени;

- в ОАО “Уралкриомаш” созданы секции более коротких (транспортабельной длины) трубопроводов, но полностью изготовленных в заводских условиях и там отвакуумированных. На объекте готовые секции стыковались и сваривались. Стыки обматывались специальной

14 ISSN 0236-3941. Вестник МГТУ им. Н.Э. Баумана. Сер. “Машиностроение”. 2016. № 2 
изоляционной лентой. Как в том, так и в другом случае внутренняя труба относительно кожуха фиксируется в радиальном направлении с помощью пальчиковых, проволочных или шариковых опор, в осевом дисками. Все они выполнены из материалов с малой теплопроводностью;

- в ОАО “Криогенмаш” и ОАО “Уралкриогенмаш” созданы ряды криогенной арматуры, удовлетворяющей требованиям низкотемпературной техники, различных диаметров и назначений. Наиболее удачное конструктивное решение найдено для арматуры, разработанной и испытанной в ОАО “Криогенмаш”. Арматура создана с проходными сечениями от 0,032 м до 0,4 м на различные давления, с коэффициентами местного сопротивления от 6,5 до 2,5. Она обеспечивает герметичность во всем диапазоне рабочих температур, имеет вакуумную изоляцию, удовлетворяет требованиям безопасности, ресурс ее работы составляет 20 лет и обеспечивает 20000 циклов срабатываний;

- разработаны стандартные конструкции сильфонных компенсаторов, различных диаметров, цапфовые и дисковые опоры, соединительные муфты, колена трубопроводов, металлорукава и другое комплектующее оборудование криогенных заправочных систем;

- впервые в стране разработан и создан крупный шаровой резервуар объемом 1400 м $^{3}$ для хранения и выдачи жидких кислорода, азота и водорода (последний - облегченный), разработана технология его изготовления и монтажа на объекте, решена проблема температурных деформаций внутреннего сосуда в процессе эксплуатации путем создания независимых систем опор внутреннего сосуда и кожуха, расположенных коаксиально [1].

Теперь при проектировании жидкостных криогенных систем основное оборудование можно выбирать из унифицированных рядов по исходным данным, не проводя прочностные и тепловые расчеты этого оборудования.

В 1970-е годы была выполнена модернизация криогенных систем заправки на Гагаринском стартовом комплексе. Хранилище было спроектировано и изготовлено в ОКБ-250 Уралвагонзавода, а разводка трубопроводов к ракете в стартовом сооружении была оставлена без изменений в соответствии с документацией ВНИИКимаша.

После модернизации хранилище жидкого кислорода, состоящее из пяти резервуаров с порошково-вакуумной изоляцией объемом $74 \mathrm{M}^{3}$ каждый, было вынесено на 100 м от стартового сооружения. Головная часть резервуаров с арматурой и трубопроводными вводами были вмонтированы в новое сооружение, в котором размещались четыре кислородных насоса, производства ООО “Контех-Крио”, производительностью 1,8 м 3 мин, что позволяло плавно менять расходы жидкого кислорода в процессе заправки ракеты. 
Заправка ракеты жидким азотом осуществлялась вытеснением жидкого азота из резервуара емкостью $33 \mathrm{~m}^{3}$, размещенного в этом же сооружении. Модернизация системы подачи азота высокого давления была осуществлена позже, в конце 1990-х годов при участии предприятия "Криосервис", путем замены износившихся насосных агрегатов.

Эти системы в модернизированном виде (трубопроводы и арматура заменены на коррозионно-стойкие, улучшена изоляция и др.) успешно функционируют и в настоящее время.

В 1980-е годы на базе созданного к этому времени криогенного оборудования нового поколения была проведена коренная модернизация системы заправки кислородом и азотом на втором стартовом комплексе “Союз” космодрома "Байконур”. Вновь было создано хранилище жидких кислорода и азота. Оно было размещено на открытом воздухе под навесом на расстоянии 200 м от стартового сооружения. Хранилище жидкого кислорода состоит из четырех резервуаров, объемом $250 \mathrm{M}^{3}$ заводского изготовления с экранно-вакуумной изоляцией, блока испарителей наддува, системы трубопроводной обвязки с экранно-вакуумной изоляцией. В состав азотной системы включены резервуар РЦГ-100/0,6 (объем $100 \mathrm{M}^{3}$ ), расположенный вблизи кислородных резервуаров, и магистральные вакуумные трубопроводы. Были сохранены схемы разводки коммуникаций по стартовому сооружению, принципы стыковки (расстыковки) системы с ракетой. Все трубопроводы были выполнены из коррозионно-стойкой стали с экранновакуумной изоляцией и новой арматурой. Заправка баков ракеты осуществлялась дистанционно методом вытеснения без существенного изменения технологии заправки.

В системе исключена необходимость подпитки хранилища жидким кислородом, в процессе заправки существенно уменьшены потери продуктов. Эти и другие научно-исследовательские и конструкторские работы обеспечили создание криогенных заправочных систем второго поколения и, в первую очередь, комплексов “Энергия-Буран” и “Зенит”. Они значительно превосходили своих предшественников по всем параметрам.

Интересная и достаточно сложная работа в КБОМ, а затем в НИИ СК им. В.П. Бармина была выполнена в 2010-2013 гг. по доработкам стартового комплекса “Союз” на космодроме “Плесецк” для обеспечения пуска новой ракеты легкого класса “Союз 2-1в” (заправка жидким переохлажденным кислородом блока "А” ракеты - 90 т и блока "И" 16,5 т). Доработка кислородной системы состояла в необходимости охлаждения кислорода в условиях смонтированной системы с ограниченными площадями для размещения оборудования охлаждения с сохранением системы для обеспечения заправки ракет “Союз 2-1a” и "Союз 2-16".

16 ISSN 0236-3941. Вестник МГТУ им. Н.Э. Баумана. Сер. “Машиностроение”. 2016. № 2 
Особенности криогенных систем для охлаждения горючего на стартовых комплексах ракеты “Союз”. В целях увеличения плотности углеводородных горючих керосина и нафтила перед заправкой в топливные баки различных модификаций ракеты “Союз" требуется их охлаждение до отрицательных температур. При этом керосин, предназначенный для заправки в топливные баки первой и второй ступеней ракеты, должен охлаждаться до среднемассовой температуры $-3 \pm 2{ }^{\circ} \mathrm{C}$, а горючее нафтил, предназначенное для заправки топливного бака третьей ступени ракеты, - до $-30 \pm 2{ }^{\circ} \mathrm{C}$. Отмеченные обстоятельства потребовали создания на стартовых комплексах "Союз” систем охлаждения горючего, которые были выполнены в НПП "Криосервис". Для различных стартовых комплексов специалистами этого предприятия по заказу КБОМ им. В.П. Бармина (а затем НИИ стартовых комплексов им. В.П. Бармина) были созданы 12 систем охлаждения горючего путем бесконтактного теплообмена с жидким азотом по схеме, приведенной на рис. 1, которые успешно функционируют и в настоящее время.

Процесс охлаждения осуществляется в секциях теплообменникаохладителя керосина путем его перекачки насосами по замкнутому контуру: емкость заправочной системы-насос-теплообменникемкость. Жидкий азот в теплообменники подается вытеснением его газообразным азотом из стационарных или транспортных резервуаров. Распределение потоков горючего и жидкого азота по секциям теплообменников осуществляется с помощью блока арматуры. После испарения и отвода от горючего необходимого количества теплоты газообразный азот отводится в дренажную систему стартового комплекса.

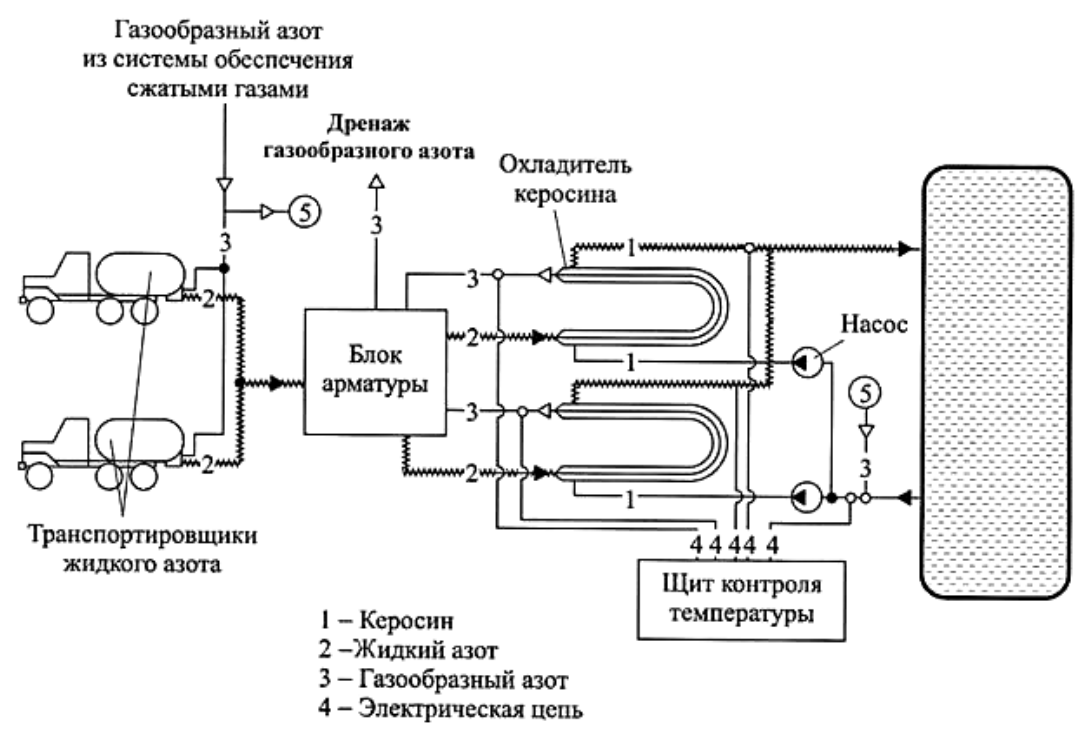

Рис. 1. Схема установки охлаждения горючего с использованием жидкого азота 
Сложность создания таких установок состояла в исключении замерзания ракетного горючего в связи с большой разностью температур между кипящим азотом и охлаждаемыми компонентами, преимущество - в исключении загрязнения окружающей среды и сохранении горючего при охлаждении в кондиции по параметрам газо- и влагосодержания.

Работы по исследованию и моделированию охлаждения компонентов ракетного топлива с использованием жидкого азота были проведены в МГТУ им. Н.Э. Баумана [2-12].

Моделирование процессов охлаждения углеводородного горючего с использованием жидкого азота и секций теплообменников типа “труба в трубе” $[2,3,7]$ позволяет прогнозировать параметры и эффективность охлаждения горючего по относительным затратам жидкого азота $\bar{m}_{\mathrm{a}}$ в зависимости от относительной массы емкости заправочной системы $\bar{m}_{\mathrm{e}}$, ее теплоемкости, расхода азота в секциях теплообменников $G_{\text {а.с.т }}$ и числа таких секций $n$ в системе охлаждения горючего с использованием следующих соотношений:

$$
\begin{aligned}
& \bar{m}_{\mathrm{a}}=-\frac{n G_{\text {a.c. } \mathrm{T}}\left(c_{\mathrm{\Gamma}}+\bar{m}_{\mathrm{e}} c_{\mathrm{e}}+n \sum \bar{m}_{i} c_{i}\right)}{k_{\mathrm{e}} F_{\mathrm{e}}+n\left(k_{\text {тр }} F_{\text {тр }}+k_{\mathrm{T}} F_{\mathrm{T}}+G_{\text {а.с. } . \mathrm{T}} c_{\mathrm{a}}\right)} \ln \frac{T_{\text {г.К }}-T_{\text {г. }}}{T_{\text {Г. }}-T_{\text {Г. }}} ; \\
& T_{\text {г.п }}=\frac{k_{\mathrm{e}} F_{\mathrm{e}} T_{\mathrm{H}}+n\left\{Q_{\mathrm{H}}+k_{\text {тр }} F_{\text {тр }} T_{\mathrm{H}}+k_{\mathrm{T}} F_{\mathrm{T}} T_{\mathrm{H}}+G_{\text {а.с.т }}\left[r_{\mathrm{a}}-c_{\mathrm{a}}\left(T_{\text {к.а }}-\Delta T_{\text {ндр }}\right)\right]\right\}}{k_{\mathrm{e}} F_{\mathrm{e}}+n\left(k_{\text {тр }} F_{\text {тр }}+k_{\mathrm{T}} F_{\mathrm{T}}+G_{\text {а.с.т }} c_{a}\right)}, \\
& \bar{m}_{\mathrm{a}}=\frac{m_{\mathrm{a}}}{m_{\mathrm{\Gamma}}} ; \quad \bar{m}_{\mathrm{e}}=\frac{m_{\mathrm{e}}}{m_{\mathrm{r}}} ; \quad \bar{m}_{i}=\frac{m_{i}}{m_{\mathrm{\Gamma}}},
\end{aligned}
$$

где $m_{\mathrm{a}}-$ масса азота, затрачиваемая на процесс охлаждения; $m_{\mathrm{r}}, m_{\mathrm{e}}-$ массы охлаждаемого горючего и емкости заправочной системы; $m_{i}$, $c_{i}$ - массы и удельные теплоемкости элементов в циркуляционном контуре горючего в секции теплообменника; $c_{\Gamma}, c_{\mathrm{e}}, c_{\mathrm{a}}$ - удельные теплоемкости горючего, емкости и газообразного азота; $k_{\mathrm{e}}, F_{\mathrm{e}}-$ коэффициент теплопередачи и площадь поверхности емкости; $T_{\mathrm{H}}-$ температура наружного воздуха; $k_{\text {тр }}, F_{\text {тр }}$ - коэффициент теплопередачи и площадь поверхности труб в контуре циркуляции горючего; $k_{\mathrm{T}}, F_{\mathrm{T}}$ коэффициент теплопередачи и площадь поверхности секции теплообменника; $T_{\text {г.н }}, T_{\text {г.к }}$ - начальная и конечная температуры горючего; $T_{\text {к.а }}-$ температура кипения азота в секции теплообменника; $\Delta T_{\text {ндр }}-$ температурный перепад недорекуперации газообразного азота в секции теплообменника; $r_{\text {a }}$ - удельная теплота кипения азота.

При моделировании процессов охлаждения горючего и характеристик оборудования контура охлаждения с использованием приведенных соотношений выявлены предпочтительные режимы подачи жидкого азота в установку при суммарных расходах $0,3 \ldots 0,6$ кг/с, при которых обеспечиваются минимальные относительные затраты

18 ISSN 0236-3941. Вестник МГТУ им. Н.Э. Баумана. Сер. “Машиностроение”. 2016. № 2 
жидкого азота на выполнение операции охлаждения. Наименьшие относительные затраты жидкого азота при охлаждении углеводородного горючего на один градус составляют 0,009. . 0,0094 1/K при тепловых сопротивлениях изоляции емкости системы заправки $0,5 \ldots 1 \mathrm{~m}^{2} \cdot \mathrm{K} / \mathrm{BT}$, что подтверждено в ходе эксплуатации системы охлаждения [3].

Использование технологий охлаждения во внешних по отношению к емкости заправочной системы теплообменниках основано на организации циркуляции топлива через теплообменники, а в случае применения технологий охлаждения с промежуточным теплоносителем - и топлива, и теплоносителя [9-11], что требует включения в систему насосов, при работе которых выделяется тепловая энергия, снижающая эффективность процессов охлаждения ракетного топлива.

Применение технологий охлаждения КРТ с использованием жидкого азота и теплообменников, размещенных непосредственно в емкости системы заправки наземного комплекса, схема которой приведена на рис. 2, не требует насосов и позволяет осуществлять режимы охлаждения топлива с большей эффективностью [12].

Температурная подготовка топлива в емкости 1 перед заправкой в ракетный бак 11 проводится посредством теплообмена с наружной поверхностью теплообменника 3. Режим охлаждения топлива осуществляется подачей жидкого азота из емкости 2 при поступлении в нее под давлением газообразного азота из хранилища газообразного азота 4 через газовый редуктор 5. Жидкий азот вводится в нижнюю часть теплообменника 3 и вследствие теплообмена с топливом переходит в

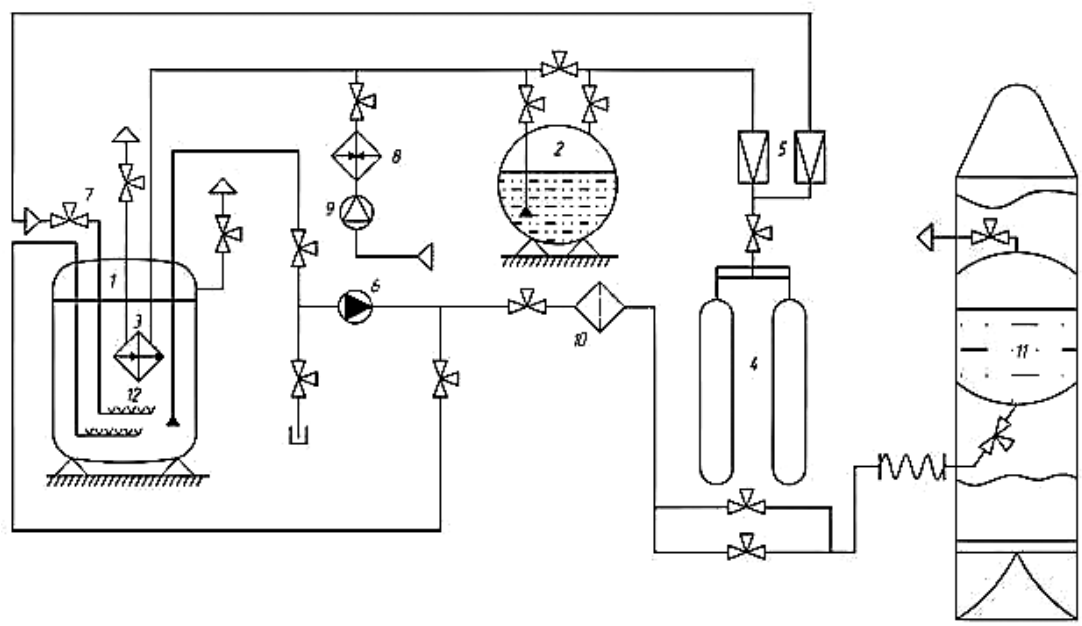

Рис. 2. Схема системы заправки жидким азотом [12] стартового комплекса с предварительным охлаждением ракетного топлива во внутреннем пространстве емкости-хранилища:

1 и 2 - емкости с топливом и жидким азотом; 3 - теплообменник; 4 - хранилище газообразного азота высокого давления; 5 - газовый редуктор; 6 - насос; 7 запорная арматура; 8 - воздухонагреватель; 9 - компрессор; $10-$ фильтр; 11 топливный бак; 12 - барботер газообразного азота

ISSN 0236-3941. Вестник МГТУ им. Н.Э. Баумана. Сер. “Машиностроение” 2016. № 219 
газообразное состояние и отводится в дренажную магистраль системы заправки наземного комплекса. Для повышения эффективности теплообмена между холодным азотом и топливом, а также исключения его намерзания на наружной поверхности теплообменника, внутренний объем теплообменника заполнен антифризом. При этом подача жидкого азота в теплообменник с антифризом происходит через барботер, что обеспечивает интенсивный теплообмен между диспергированным жидким азотом и антифризом и через стенку теплообменника - с топливом. Для перемешивания и выравнивания температуры топлива в емкости может использоваться насос 6 заправочной системы. Для достижения той же цели может использоваться барботаж емкости сухим газообразным азотом через барботер 12. При этом происходит удаление из топлива растворенной воды. После охлаждения топлива до требуемой температуры, в случае применения для перемешивания и обезвоживания топлива барботажа сухим азотом, проводится операция рассыщения топлива [12].

Результаты численного моделирования изменения температур горючего нафтил в емкости заправочной системы с расположенным в ней теплообменником с антифризом А-65 при охлаждении жидким азотом, приведенные на рис. 3 , свидетельствуют о возможности проведения операции охлаждения топлива за сравнимый период, выполняемой штатной системой охлаждения [2, 3].

При этом исключается опасность намерзания топлива на теплообменных поверхностях за счет охлаждения и поддержания температуры антифриза выше температуры затвердевания топлива, что достигается уменьшением расхода подачи жидкого азота в теплообменник с антифризом и приводит к уменьшению затрат криогенного продукта на выполнение операции охлаждения топлива [12].

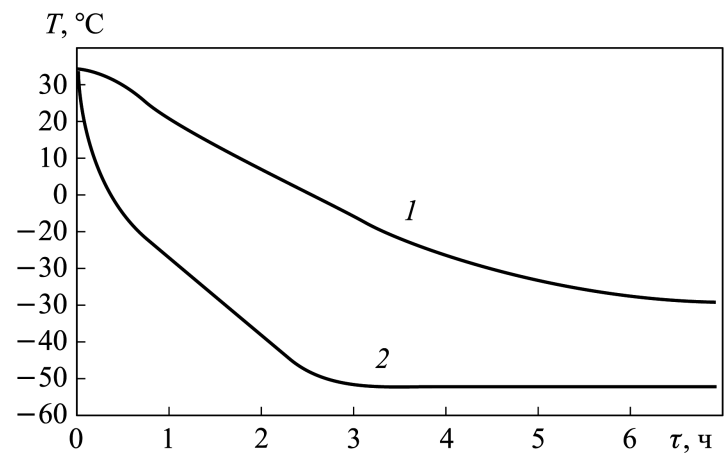

Рис. 3. Результаты моделирования изменения температуры горючего нафтил в емкости заправочной системы третьей ступени ракеты-носителя "Союз" при выполнении операции охлаждения с использованием жидкого азота и теплообменника, расположенного во внутреннем пространстве емкости:

1 - температура горючего; 2 - температура антифриза А-65

20 ISSN 0236-3941. Вестник МГТУ им. Н.Э. Баумана. Сер. “Машиностроение”. 2016. № 2 


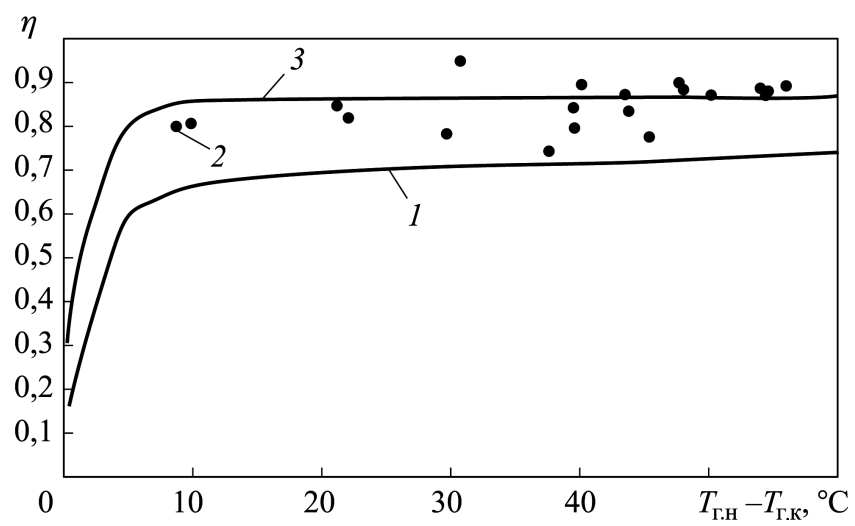

Рис. 4. Изменение КПД систем охлаждения жидким азотом горючего в зависимости от уровня понижения его температуры:

1 - результаты численного моделирования при охлаждении горючего с использованием жидкого азота и теплообменника, размещенного непосредственно в емкости системы заправки; 2, 3 - экспериментальные [3] и расчетные значения при охлаждении горючего методом криогенного барботажа

Эффективность процесса охлаждения горючего для различных вариантов построения систем охлаждения при использовании в качестве источника холода жидкого азота может оцениваться по значению КПД ( $\eta$ ) системы охлаждения, который определяется соотношением

$$
\eta=\frac{1}{\bar{m}_{\mathrm{a}}} \frac{\bar{c}_{\Gamma}\left(T_{\text {Г.н }}-T_{\text {Г.К }}\right)}{r_{\mathrm{a}}+\bar{c}_{\mathrm{a}}\left(\bar{T}_{\text {Г }}-T_{\text {к.a }}\right)},
$$

где $\bar{T}_{\mathrm{r}}, \bar{c}_{\mathrm{r}}, \bar{c}_{\mathrm{a}}-$ средние значения температуры и удельной теплоемкости горючего и удельной теплоемкости азота в диапазоне температур $T_{\text {г.н }} \ldots T_{\text {г.К. }}$.

На рис. 4 приведены экспериментальные значения и данные моделирования по изменению коэффициента $\eta$ в зависимости от уровня понижения температуры горючего нафтил в емкости заправочной системы для нескольких вариантов построения системы охлаждения горючего с использованием жидкого азота.

По результатам моделирования КПД системы охлаждения горючего с использованием жидкого азота и теплообменника, размещенного непосредственно в емкости системы заправки, на 0,2-0,3 выше по сравнению с технологией охлаждения ракетного топлива с использованием внешних теплообменников типа “труба в трубе” при теплообмене с кипящим жидким азотом, и только на 0,1-0,15 уступает технологии охлаждения топлива методом криогенного барботажа $[3,10]$. При этом технология охлаждения ракетного топлива с использованием жидкого азота и теплообменников применима к любым высококипящим КРТ, в отличие от метода криогенного барботажа, который применим только к углеводородным горючим. 


\section{Характеристики криогенных систем стартового комплекса ра-}

кеты “Союз-СТ". С помощью ракетных комплексов ракеты Р-7 и ее модификаций в РФ осуществлены многие грандиозные задачи в освоении космического пространства. Стартовые комплексы и, естественно, криогенное оборудование были модернизированы для осуществления пусков различных модификаций ракеты. Были доработаны криогенные системы для усовершенствованной ракеты Р-7А, 4-ступенчатой ракеты "Молния", 3-ступенчатых ракет “Луна", "Восток", "Восход”, “Союз-У”, “Союз-ФГ” и “Союз-2”. Эти системы являются прототипом созданных в начале XXI в. криогенных систем заправки жидкими кислородом и азотом на космодроме во французской Гвиане для ракеты “Союз-СТ”, основные характеристики которых приведены ниже.

Технические характеристики системь заправки жидким кислородом ракеть "Союз-СТ"

Число резервуаров жидкого кислорода, шт.............. 3

Вместимость внутреннего сосуда резервуара, м $\ldots \ldots \ldots . .207$

Максимальная масса жидкого кислорода в резервуаре, кг .... 224200

Способ выдачи продукта ........................ Вытеснительный

Количество жидкого кислорода, заправляемого в топливные ба-

ки ракеты, т................................. 192

Максимальный расход жидкого кислорода, кг/с, при:

заправке блоков 1-й и 2-й ступеней ................. 27,903

заправке блоков 3 -й ступени ...................... 15,677

захолаживании ................................. 1,45

заправке ................................... 20-50

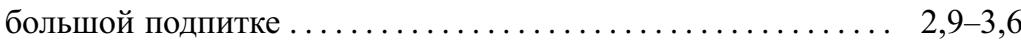

малой подпитке ........................... $0-0,68$

Температура жидкого кислорода на входе в блоки при заправке, не более, К................................ 92

Диаметр заправочной магистрали, мм............... 250

Технические характеристики системы заправки жидким азотом для ракеть "Союз-СТ"

Число резервуаров жидкого азота, шт. .................. 1

Вместимость внутреннего сосуда резервуара, м $^{3} \ldots \ldots \ldots \ldots \ldots 112$

Максимальная масса жидкого азота в резервуаре, кг ......... 85760

Количество жидкого азота, заправляемого в баки ракеты, т:

блок 1 -й ступени .................................. 280

блок 2-й ступени ............................. 522

Расход жидкого азота, кг/с, при:

заправке бака ................................. $0,9-1,0$

подпитке бака............................... $0,16-0,17$

Температура на входе в ракету на режиме заправки, К ........ 82

Давление (избыточное) в баках ракеты на режиме, МПа:

охлаждения и заправки .......................... 0,2

подпитки .................................... 0,06

Диаметр заправочной магистрали, мм ................ 65

22 ISSN 0236-3941. Вестник МГТУ им. Н.Э. Баумана. Сер. “Машиностроение”. 2016. № 2 
Технические характеристики системы охлаждения керосина (нафтила) жидким азотом на стартовом комплексе ракеты "Союз-СТ"

Число резервуаров жидкого азота, шт. ................ 1

Вместимость внутреннего сосуда резервуара, м $^{3} \ldots \ldots \ldots \ldots \ldots 112$

Масса жидкого азота в резервуаре, кг ............... Не более 85760

Количество охлаждаемого керосина в заправщике, кг:

железнодорожном .......................... 85000

автомобильном.................................. 10500

Минимальная температура охлаждения горючего в заправщике, ${ }^{\circ} \mathrm{C}$ :

железнодорожном ................................ $-3 \pm 2$

автомобильном................................ 34

Расход горючего через каждый охладитель, м $^{3} /$ ч . . . . . . 30

Максимальное время охлаждения горючего в железнодорожном заправщике, ч:

при работе одного насоса $\ldots \ldots \ldots \ldots \ldots \ldots \ldots \ldots \ldots \ldots \ldots . . \ldots \ldots$

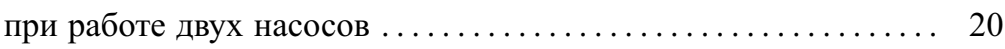

в автомобильном заправщике при работе одного насоса ...... 4

В результате реализации проекта “Союз” в Гвианском космическом центре был создан комплекс запуска (рис. 5) с криогенными системами с самыми высокими техническими характеристиками по сравнению с другими зарубежными и отечественными аналогами.

Комплекс подготовки запуска ракеты “Союз-СТ” отличается компактностью (его площадь в разы меньше, чем у аналогов), удобством эксплуатации. Численность расчета пуска на нем в 2 раза меньше, чем на аналогичных комплексах на космодромах "Байконур" и “Плесецк".

Многие технические решения по криогенным системам используются в настоящее время при создании космодрома "Восточный".

Заключение. Полученный опыт при создании и модернизации криогенных систем на стартовых комплексах ракет-носителей “Союз” и созданная научно-техническая база криогенной техники позволяют использовать ряды основных комплектующих элементов (резервуары, секции трубопроводов, арматуру, приборы, компенсационные узлы и др.) для создания современных криогенных систем для заправки ракет жидкими криогенными продуктами. В связи с этим в настоящее время к работам по созданию новых систем заправки ракет криогенным топливом специализированные предприятия привлекаются только на стадии рабочего проектирования и изготовления оборудования. На более ранних стадиях работы проводит головная организация по стартовому комплексу.

С помощью ракетных комплексов ракеты Р-7 и ее модификаций в РФ осуществлены многие грандиозные задачи в освоении космического пространства. Стартовые комплексы и, естественно, криогенное оборудование прошли многоэтапный путь развития, позволивший в 


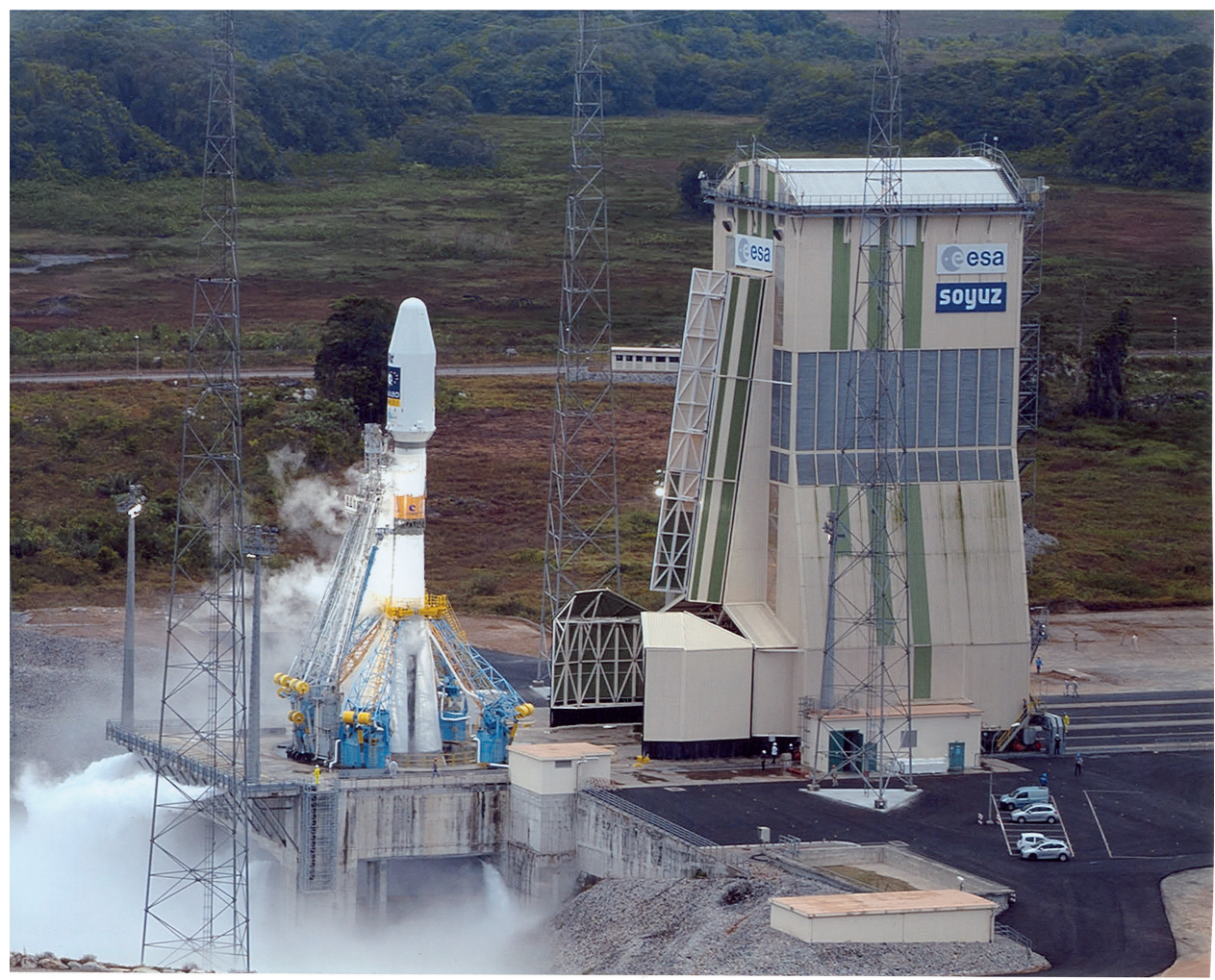

Рис. 5. Стартовый комплекс ракеты “Союз-СТ" при выполнении операций заправки криогенными продуктами

настоящее время иметь в России и за рубежом конкурентоспособные ракетно-космические стартовые комплексы с высокоэффективными криогенными системами для ракет-носителей “Союз-2” и “СоюзСТ” (включая ракеты-носители среднего и легкого классов), которые имеют реальные перспективы использования на ближайшие десятилетия. Ракетно-космические комплексы “Союз” прочно заняли лидирующее положение на мировом рынке пусковых услуг в своем классе, а российские предприятия - производители ракетно-космической техники и поставщики пусковых услуг обеспечены гарантированными заказами на ближайшую и долгосрочную перспективу.

\section{ЛИТЕРАТУРА}

1. Архаров А.М., Кунис И.Д. Криогенные заправочные системы стартовых ракетно-космических комплексов / под ред. И.В. Бармина. М.: Изд-во МГТУ им. Н.Э. Баумана, 2006. 252 с.

2. Александров А.А., Гончаров Р.А., Игрицкий В.А., Чугунков В.В. Методика выбора рациональных режимов охлаждения углеводородного горючего стартовым оборудованием перед заправкой топливных баков ракеты-носителя // Вестник МГТУ им. Н.Э. Баумана. Сер. Машиностроение. 2011. № 1. С. 40-46.

3. Александров А.А., Денисов О.Е., Золин А.В., Чугунков В.В. Охлаждение ракетного топлива стартовым оборудованием с применением жидкого азота // Известия высших учебных заведений. Машиностроение. 2013. № 4. С. 24-29.

24 ISSN 0236-3941. Вестник МГТУ им. Н.Э. Баумана. Сер. “Машиностроение”. 2016. № 2 
4. Золин A.B., Чугунков B.B. К выбору технического облика и рациональных параметров систем охлаждения и обезвоживания для хранилищ углеводородного горючего космодромов // Известия высших учебных заведений. Машиностроение. 2012. Спец. вып. "Работы студентов и молодых ученых МГТУ им. Н.Э. Баумана". С. 39-42.

5. Кобызев C.В., Золин А.В., Чугунков В.В. Построение рациональной схемы подготовки углеводородного горючего по температуре и влагосодержанию с использованием жидкого и газообразного азота на стартовом и техническом комплексах космодрома // Наука и образование. МГТУ им. Н.Э. Баумана. 2012. № 10. URL: http://technomag.bmstu.ru/doc/486647.html DOI: 10.7463/1012.0486647

6. Денисов О.Е., Золин А.В., Денисова К.И. Методика проектирования базы хранения и подготовки высококипящих компонентов ракетного топлива космодрома “Восточный” // Наука и образование. МГТУ им. Н.Э. Баумана. 2014. № 11. URL: http://technomag.bmstu/doc/732218.html DOI: 10.7463/1114.0732218

7. Гончаров Р.A., Чугунков В.В. Определение параметров и режимов работы стартового оборудования по охлаждению углеводородного горючего перед заправкой в бортовые баки ракеты-носителя // Известия высших учебных заведений. Машиностроение. 2012. Спец. вып. "Работы студентов и молодых ученых МГТУ им. Н.Э. Баумана". С. 34-38.

8. Денисов О.Е., Золин А.В., Чугунков В.В. Методика моделирования охлаждения компонентов ракетного топлива с применением жидкого азота и промежуточного теплоносителя // Наука и образование. МГТУ им. Н.Э. Баумана. 2014. № 3. C. 145-161. URL: http://technomag.bmstu.ru/issue/699215.html DOI: $10.7463 / 0314.0699941$

9. Павлов С.К., Чугунков В.В. Математическая модель процесса температурной подготовки компонентов жидкого ракетного топлива с использованием теплообменника и теплоносителя, охлаждаемого жидким азотом // Наука и образование. МГТУ им. Н.Э. Баумана. 2014. № 12. С. 128-136.

URL: http://technomag.bmstu.ru/doc/744330.html DOI: 10.7463/0815.9328000

10. Золин A.B., Чугунков B.B. Моделирование процессов температурной подготовки ракетного горючего в системе заправки стартового комплекса. Аэрокосмический научный журнал. Сетевое издание. МГТУ им. Н.Э. Баумана. 2015. № 11. URL: http://aerospjournal.ru/doc/826690.html DOI: 10.7463/aersp.0615.0826690

11. Павлов С.К., Чугунков В.В. Сравнительный анализ математических моделей температурной подготовки компонентов жидкого ракетного топлива с использованием теплообменника и теплоносителя, охлаждаемого жидким азотом // В сб.: Молодежь и XXI век - 2015. Материалы V Междунар. молодеж. науч. конф. 2015. С. 191-195.

12. Денисова К.И., Чугунков В.В. Моделирование процессов охлаждения и нагрева ракетного топлива во внутреннем пространстве емкостей наземных комплексов // Аэрокосмический научный журнал. Сетевое издание. МГТУ им. Н.Э. Баумана. 2016. № 1. URL: http://aerospjournal.ru/doc/834621.html

DOI: $10.7463 /$ aersp.0116.0834621

\section{REFERENCES}

[1] Arharov A.M., Kunis I.D., ed. by I.V. Barmin. Kriogennye zapravochnye sistemy startovykh raketno-kosmicheskikh kompleksov [The cryogenic filling system launch rocket-space complexes]. Moscow, MGTU im. N.E. Baumana Publ., 2006. 252 p.

[2] Aleksandrov A.A., Goncharov R.A., Igritskiy V.A., Chugunkov V.V. Methodology of Selection of Rational Regimes for Cooling the Hydrocarbon Fuel by Launch Equipment before Filling of Fuel Tanks of Launch Vehicle. Vestn. Mosk. Gos. Tekh. Univ. im. N.E. Baumana, Mashinostr. [Herald of the Bauman Moscow State Tech. Univ., Mech. Eng.], 2011, no. 1, pp. 40-46 (in Russ.).

ISSN 0236-3941. Вестник МГТУ им. Н.Э. Баумана. Сер. “Машиностроение” 2016. № 225 
[3] Aleksandrov A.A., Denisov O.E., Zolin A.V., Chugunkov V.V. Refrigerating Rocket Fuel by Launching Equipment with the Use of Liquid Nitrogen. Izv. Vyssh. Uchebn. Zaved., Mashinostr. [Proc. of Higher Educational Institutions. Machine Building], 2013, no. 4, pp. 24-29 (in Russ.).

[4] Zolin A.V., Chugunkov V.V. Technique to analyze heatexchange processes of rocket fuel components when performing operation of rocket fuel tanks filling at the starting complex. Izv. Vyssh. Uchebn. Zaved., Mashinostr., Spetsvyp. [Proc. of Higher Educational Institutions. Machine Building, Spec. Issue "Collected papers of students and young scientists of the Bauman MSTU”], 2012, pp. 39-42 (in Russ.).

[5] Kobizev S.V., Zolin A.V., Chugunkov V.V. Building a rational scheme of preparation of hydrocarbon fuels according to temperature and moisture content with use of liquid and gaseous nitrogen at launch and technical spaceport complexes. Nauka i obrazovanie. MGTU im. N.E. Baumana [Science \& Education of the Bauman MSTU. Electronic Journal], 2012, no. 10. Available at: http://technomag.bmstu.ru/en/doc/486647.html DOI: 10.7463/1012.0486647

[6] Denisov O.E., Zolin A.V., Denisova K.I. Design Technique for the HighBoiling Propellant Storage and Preparation Facility at the Cosmodrome "Vostochny". Nauka i obrazovanie. MGTU im. N.E.Baumana [Science \& Education of the Bauman MSTU. Electronic Journal], 2014, no. 11. Available at: http://technomag.bmstu.ru/en/doc/732218.html DOI: 10.7463/1114.0732218

[7] Goncharov R.A., Chugunkov V.V. Determining parameters and modes of starup equipment operation to cool hydrocarbon fuel before fuelling the carrier rocket onboard tanks. Izv. Vyssh. Uchebn. Zaved., Mashinostr., Spetsvyp. [Proc. of Higher Educational Institutions. Machine Building, Spec. Issue "Collected papers of students and young scientists of the Bauman MSTU"], 2012, pp. 34-38 (in Russ.).

[8] Denisov O.E., Zolin A.V., Chugunkov V.V. Simulation methods of rocket fuel refrigerating with liquid nitrogen and intermediate heat carrier. Nauka i obrazovanie. MGTU im. N.E. Baumana [Science \& Education of the Bauman MSTU. Electronic Journal], 2014, no. 3. Available at: http://technomag.bmstu.ru/en/issue/699215.html DOI:10.7463/0314.0699941

[9] Pavlov S.K., Chugunkov V.V. Mathematical Model-Based Temperature Preparation of Liquid-Propellant Components Cooled by Liquid Nitrogen in the Heat Exchanger with a Coolant. Nauka $i$ obrazovanie. MGTU im. N.E. Baumana [Science \& Education of the Bauman MSTU. Electronic Journal], 2014, no. 12. Available at: http://technomag.bmstu.ru/en/doc/744330.html DOI: 10.7463/1214.0744330

[10] Zolin A.V., Chugunkov V.V. Modeling of thermal processes of preparation of rocket fuel in the fueling system of the launch complex. Aerospace scientific journal of the Bauman MSTU, 2015, no. 11. Available at: http://aerospjournal.ru/doc/826690.html DOI: 10.7463 /aersp.0615.0826690

[11] Pavlov S.K., Chugunkov V.V. Comparative Analysis of Mathematical Models of the Temperature of Preparant of Liquid Propellant Components Using a Exchanger and Coolant Cooled by Liquid Nitrogen. In Digest: Youth and 21 age-2015. Materials of V International Scientific Conf., 2015, pp. 191-195 (in Russ.).

[12] Denisova K.I., Chugunkov V.V. Modeling of processes of heating and cooling of rocket fuel in the interior space of tanks ground-based complexes. Aerospace Scientific journal of the Bauman MSTU, 2016, no. 1. Available at: http://aerospjournal.ru/doc/834621.html DOI: 10.7463/aersp.0116.0834621

Статья поступила в редакцию 21.12.2015

Александров Анатолий Александрович - ректор МГТУ им. Н.Э. Баумана, д-р техн. наук, профессор кафедры “Стартовые ракетные комплексы” МГТУ им. Н.Э. Баумана (Российская Федерация, 105005, Москва, 2-я Бауманская ул., д. 5).

Aleksandrov A.A. - Rector of Bauman Moscow State Technical University, Dr. Sci. (Eng.), Professor of Launch Rocket Complexes Department, Bauman Moscow State Technical University (2-ya Baumanskaya ul. 5, Moscow, 105005 Russian Federation).

26 ISSN 0236-3941. Вестник МГТУ им. Н.Э. Баумана. Сер. “Машиностроение”. 2016. № 2 
Бармин Игорь Владимирович - д-р техн. наук, член-корр. РАН, профессор, зав. кафедрой “Стартовые ракетные комплексы” МГТУ им. Н.Э. Баумана (Российская Федерация, 105005, Москва, 2-я Бауманская ул., д. 5), генеральный конструктор предприятия “Центр эксплуатации объектов наземной космической инфраструктуры” (Российская Федерация, 107996, Москва, ул. Щепкина, д. 42).

Barmin I.V. - Dr. Sci. (Eng.), Corresponding Member of the Russian Academy of Sciences, Head of Launch Rocket Complexes Department, Bauman Moscow State Technical University (2-ya Baumanskaya ul. 5, Moscow, 105005 Russian Federation), General Designer of Federal State Unitary Enterprise, Centre of Ground Space Infrastructure Exploitation (Shepkina ul. 42, Moscow, 107996 Russian Federation).

Кунис Илья Давыдович - канд. техн. наук, начальник отдела криогенных систем предприятия “Центр эксплуатации объектов наземной космической инфраструктуры” (Российская Федерация, 107996, Москва, ул. Щепкина, д. 42).

Kunis I.D. - Cand. Sci. (Eng.), Head of Cryogenic Systems Design Department, Federal State Unitary Enterprise, Centre of Ground Space Infrastructure Exploitation (Shepkina ul. 42, Moscow, 107996 Russian Federation).

Чугунков Владимир Васильевич - д-р техн. наук, профессор кафедры “Стартовые ракетные комплексы” МГТУ им. Н.Э. Баумана (Российская Федерация, 105005, Москва, 2-я Бауманская ул., д. 5).

Chugunkov V.V. - Dr. Sci. (Eng.), Professor of Launch Rocket Complexes Department, Bauman Moscow State Technical University (2-ya Baumanskaya ul. 5, Moscow, 105005 Russian Federation).

\section{Просьба ссылаться на эту статью следующим образом:}

Александров А.А., Бармин И.В., Кунис И.Д., Чугунков В.В. Особенности создания и развития криогенных систем ракетно-космических стартовых комплексов “Союз” // Вестник МГТУ им. Н.Э. Баумана. Сер. Машиностроение. 2016. № 2. C. 7-27. DOI: 10.18698/0236-3941-2016-2-7-27

\section{Please cite this article in English as:}

Aleksandrov A.A., Barmin I.V., Kunis I.D., Chugunkov V.V. Characteristic features of creating and developing cryogenic systems of space-rocket launch complex "Soyuz". Vestn. Mosk. Gos. Tekh. Univ. im. N.E. Baumana, Mashinostr. [Herald of the Bauman Moscow State Tech. Univ., Mech. Eng.], 2016, no. 2, pp. 7-27. DOI: 10.18698/0236-3941-2016-2-7-27 